\title{
Anticholinergic syndrome following an unintentional overdose of scopolamine
}

This article was published in the following Dove Press journal:

Therapeutics and Clinical Risk Management

10 September 2009

Number of times this article has been viewed

\author{
Carmela E Corallo' \\ Ann Whitfield ${ }^{2}$ \\ Adeline $\mathrm{Wu}^{2}$ \\ 'Department of Pharmacy, \\ The Alfred, Melbourne, Victoria, \\ Australia; ${ }^{2}$ Intensive Care Unit, \\ Box Hill Hospital, Melbourne, \\ Victoria, Australia
}

Correspondence: Carmela E Corallo Pharmacy Department, Alfred Hospital, 55 Commercial Road,Victoria 318I Australia

Tel +6I 397065313

Fax +6I 390765275

Email c.corallo@alfred.org.au

\begin{abstract}
Scopolamine hydrobromide (hyoscine) is an antimuscarinic drug which is primarily used in the prophylaxis and treatment of motion sickness and as a premedication to dry bronchial and salivary secretions. In acute overdosage, the main clinical problem is central nervous system (CNS) depression. In Australia, tablets containing scopolamine hydrobromide $0.3 \mathrm{mg}$ are available over the counter in packs of ten. The recommended dose for adults is one to two tablets as a single dose, repeated four to six hours later, if required. The maximum dose stated on the pack is four tablets over a 24-hour period with a caution regarding drowsiness and blurred vision. We describe a patient who presented with symptoms of anticholinergic syndrome secondary to an unintentional overdose of scopolamine. Whilst at work, the patient noticed that he had forgotten his prescribed medication, domperidone, at home; a friend gave him some travel sickness medication which contained scopolamine for relief of nausea. On a previous occasion, he had experienced a similar, less severe reaction with another anticholinergic agent, loperamide. This report highlights the need to consider nonprescription products, ie, over the counter medications, herbal/nutritional supplements as causes of anticholinergic syndrome when a patient presents with symptoms suggestive of this diagnosis.
\end{abstract}

Keywords: domperidone, scopolamine, nonprescription drugs, toxicity, anticholinergic syndrome

Anticholinergic syndrome is a well described toxidrome produced by the inhibition of cholinergic neurotransmission at muscarinic receptor sites. This may involve peripheral receptors (eg, in the heart, salivary glands, sweat glands, gastrointestinal tract, and genitourinary tract) with resulting tachycardia, hyperthermia, dry skin and mucous membranes, mydriasis, decreased bowel sounds and urinary retention. ${ }^{1}$ Central nervous system (CNS) receptors may also be affected with resulting hallucinations, psychoses, seizures, and coma, which generally occurs late in the course of the syndrome. The central anticholinergic syndrome occurs frequently, but is often unrecognized because many patients' symptoms do not appear in a well defined pattern. The response to medications varies among patients, and there is temporal fluctuation in the course of an anticholinergic syndrome. ${ }^{2}$ The syndrome has been reported following the ingestion of a wide variety of prescription and over-the-counter medications. ${ }^{1,3}$

Scopolamine hydrobromide (also known as hyoscine hydrobromide) is an antimuscarinic drug which has been used for the treatment of motion sickness in a transdermal application, as an anesthetic premedication inducing sedation and reduction of secretions in the oropharynx and the bronchi. ${ }^{4}$ It is the single most effective agent to prevent 
motion sickness. ${ }^{5}$ Doses vary according to the indication with a maximum oral daily dose of $1.2 \mathrm{mg} .{ }^{4}$ Being a tertiary amine, scopolamine hydrobromide is easily absorbed after oral intake and penetrates the blood-brain barrier by passive diffusion. It is important to note that scopolamine hydrobromide and scopolamine butylbromide are different in many aspects. Both are available as nonprescription products in Australia. Scopolamine butylbromide is a quaternary amine compound that is poorly absorbed ( $2 \%-10 \%$ of an oral dose) and cannot readily penetrate the blood-brain barrier, therefore CNS effects are rare. The maximum daily oral dose is $80 \mathrm{mg}$ per day. ${ }^{4}$

The pharmacokinetic parameters of scopolamine hydrobromide are dependent on the dose form. ${ }^{6}$ It has limited bioavailability when orally administered with an absolute bioavailability reported to range between $3 \%$ and $27 \%$; a first pass metabolism is believed to occur. Maximum plasma levels have occurred $23.5 \pm 8.2$ minutes following oral administration. After ocular administration, scopolamine hydrobromide is rapidly, efficiently and systemically absorbed. Following transdermal application in one study, delivery of scopolamine resulted in a pattern of systemic availability which was comparable with an intravenous infusion, which suggests a high bioavailability. Although scopolamine has been used in clinical practice for many years, data concerning its metabolism and renal excretion are limited. It appears that glucuronide conjugation is the relevant pathway. ${ }^{6}$ There is no data suggesting involvement of the hepatic cytochrome system.

Scopolamine administered in pharmacologically effective doses, unlike atropine and other antimuscarinic agents, produces CNS depressive effects such as drowsiness, amnesia, fatigue and dreamless sleep. ${ }^{6,7}$ High doses can lead to CNS stimulation (eg, excitement, restlessness, irritability, hallucinations, and delirium) which is similar to the effect observed with toxic doses of other muscarinic agents. In fact, symptoms observed in patients following scopolamine intoxication suggest a dose-dependent CNS effect. ${ }^{8}$ However, potentially alarming, idiosyncratic reactions may occur with therapeutic doses of scopolamine hydrobromide..$^{9,10}$ The most serious idiosyncratic reaction is acute psychosis with this described as confusion, agitation, rambling speech, hallucinations, paranoid behavior, and delusions. Other manifestations may include somnolence, dilated pupils, accelerated pulse rate, and dryness of the mouth with a husky quality of the voice. ${ }^{10}$ Any or all of these signs may occur with overdose or as adverse reactions involving anticholinergic drugs. ${ }^{11}$
Scopolamine hydrobromide differs strikingly from atropine in that it does not stimulate the medullary centers and therefore does not increase respiration or elevate blood pressure. It frequently appears to act as a cerebral depressant and tends to promote sleep. A striking effect of large doses of scopolamine hydrobromide is the loss of memory for events that happened while the patient was under the influence of the drug. ${ }^{9}$

The range of toxicity for scopolamine hydrobromide is variable and unpredictable. ${ }^{11}$ Symptoms and signs of anticholinergic poisoning may occur following oral ingestion or ocular instillation of as little as 4-5 drops of eye drops containing $0.25 \%$ of scopolamine hydrobromide. ${ }^{11,12}$ It is important to note that pharmacokinetic-pharmacodynamic studies of the therapeutic use of scopolamine hydrobromide have shown a delay between the maximal scopolamine concentration and the maximal presentation of neurological effects. ${ }^{4}$

An oral dose of $50 \mathrm{mg}$ atropine sulfate in humans has been reported to be fatal, but exact data on lethal doses of scopolamine are lacking. Ingestion of $10 \mathrm{mg}$ has been reported to be lethal in children, whereas adults have survived more than $100 \mathrm{mg} .{ }^{8,13}$ A dose of $0.45 \mathrm{mg}$ of scopolamine (five drops of a $0.25 \%$ scopolamine ophthalmic solution) has caused toxic psychosis which lasted 10 days. ${ }^{14}$ However, it is not clear if this involved oral or ocular administration. In addition, the source of this statement cannot be verified. ${ }^{15}$

In a study involving 115 patients following acute poisoning from over the counter sleep preparations containing scopolamine in combination with an antihistamine lowest ingested dose producing life-threatening symptoms (eg, convulsions, arrhythmias, hallucinations) was 2-4 mg. ${ }^{3}$ This data has been subsequently inappropriately quoted by other authors as a lethal dose for scopolamine. ${ }^{16}$ Lauwers and colleagues describe eight patients who were admitted to hospital after drinking tea or coffee adulterated with scopolamine, as confirmed by toxicological examinations. ${ }^{8}$ First signs of toxicity included a feeling of weakness and lassitude in the lower limbs, quickly followed by visual disturbances, blurred vision and dry mouth. Subsequently the patients became confused, agitated, and developed hallucinations. All exhibited cycloplegia, extreme mydriasis, and had warm and dry skin. In general there was moderate tachycardia with normal blood pressure and respiratory pattern. All had normal body temperature and none had signs of CNS depression. All showed amnesia as from the appearance of the hallucinations until return of normal consciousness. 
There is also a case report of a ten-and-a-half-year-old boy with acute onset of confusion and visual hallucinations subsequently confirmed to be due to scopolamine toxicity following ingestion of travel sickness medication. ${ }^{17}$ The amount of scopolamine hydrobromide ingested was $2.4 \mathrm{mg}$. Van Sassenbrocck and colleagues describe three patients who received $10 \mathrm{mg}$ of scopolamine hydrobromide as an accidental overdose due to compounding errors instead of scopolamine butylbromide. ${ }^{4}$ In some cases, symptoms persisted for months and in one case the patient had been mistakenly diagnosed as suffering a stroke.

Widespread scopolamine toxicity occurred in Australia due to a manufacturing error resulting in an over-the-counter travel sickness preparation. ${ }^{18}$ Symptoms described in the reports were a combination of hallucinations, confusion, ataxia, and blurred vision.

The anticholinergic syndrome is a well documented side effect of transdermal scopolamine. ${ }^{19-21}$ There is a case report describing an intensive care unit (ICU) patient who experienced neurological deterioration and bilateral mydriasis six hours after application of a patch containing $1 \mathrm{mg}$ of scopolamine to reduce bronchial secretions. ${ }^{22}$ Symptoms resolved after removal of the patch. Kranke and colleagues performed a systematic review of randomized controlled trials published between 1984 and 1996 to evaluate the efficacy and safety of transdermal scopolamine when used for the prevention of postoperative nausea and vomiting. Based on data from 23 such trials, the authors estimate the incidence of side-effects to be as follows: visual disturbances, $18 \%$; dry mouth, $8 \%$; dizziness, $2 \%$; and agitation, $1 \%{ }^{23}$

Domperidone is a dopamine antagonist that is commonly used as an antiemetic and in the treatment of gastroparesis. Although structurally related to metoclopromide, it does not cross the blood-brain barrier and has not been reported to cause significant CNS side effects. ${ }^{24}$ Despite its low degree of CNS activity, domperidone is an effective antiemetic. This efficacy reflects its activity at the chemoreceptor trigger zone which is located in the fourth ventricle of the brain but outside the blood-brain barrier. Domperidone is distinguished from other prokinetic agents in that it has no cholinergic activity and its action is not inhibited by atropine. With oral domperidone, side effects occur in fewer than $7 \%$ of patients and include headaches, dry mouth, diarrhea, anxiety, and prolactin-related findings, eg, breast tenderness and enlargement, galactorrhea (uncommon), and menstrual irregularities. The maximum daily dose of domperidone recommended by the manufacturer is $80 \mathrm{mg}$, however doses as high as $120 \mathrm{mg}$ a day may be required in some patients.
The main metabolic pathway of domperidone is through CYP3A4. In vitro and human data show that concomitant use of drugs that significantly inhibit this enzyme (eg, azole antifungals, macrolide antibiotics, amiodarone) may result in increased plasma levels of domperidone; high concentrations domperidone may prolong the QT interval. ${ }^{25}$

\section{Case presentation}

A 42-year-old truck driver presented to the emergency department (ED) disoriented and agitated. He was accompanied by his wife. Because of his altered state of consciousness, he was unable to provide a medical history. According to his wife, the patient had a history of gastoparesis of unknown origin for which he had been prescribed domperidone $20 \mathrm{mg}$ four times a day. His past history was unremarkable except for a hernia repair. There was no history of alcohol abuse and he was not taking any other medications. He had omitted to take his usual lunchtime dose of domperidone because he had left his tablets at home. When he arrived home, he ingested $60-80 \mathrm{mg}$ domperidone as a single dose because of increasing nausea. Three hours later, the patient started to ramble and to behave inappropriately, becoming agitated and confused.

On presentation to the ED, the patient was noted to be disorientated and appeared to be responding to visual and auditory hallucinations; he was trying to touch imaginary objects. The Glasgow Coma Score (GCS) was 13/15. Presenting vital signs were pulse rate 100 beats/min, respiratory rate $20 / \mathrm{min}$, temperature $37.8^{\circ} \mathrm{C}$, and blood pressure 123/74 mmHg. Abnormal findings on physical examination were warm, dry skin, dilated pupils, and repeated myoclonic jerking of the jaw and limbs. Initial diagnosis included intracranial hemorrhage and metabolic causes. Investigations performed revealed electrolyte levels, thyroid function tests, glucose levels, and renal function all within normal limits. Blood alcohol, salicylate, and acetaminophen levels were not detectable. An electrocardiogram showed sinus rhythm. A computed tomography of the brain was normal.

A toxicology opinion was sought and symptoms were considered to be consistent with a central anticholinergic syndrome. Two doses of midazolam $5 \mathrm{mg}$, intramuscularly were given 10 minutes apart for the management of increasing agitation and the myoclonic jerking. Postsedation, the patient's conscious state deteriorated rapidly (GCS 3/15) and he required intubation for airway protection. He was admitted to the ICU. An indwelling urinary catheter was inserted. In the ICU, sedation was initially maintained with propofol 5-10 $\mathrm{ml} /$ hour for tube tolerance. The patient was afebrile, 
hemodynamically stable, co-operative and pleasant, with good urine output. He improved rapidly and was extubated three hours after arriving in ICU.

After the patient was extubated, there was some recall returning from the previous day's events. Upon repeated questioning, it was revealed that approximately 5-6 hours prior to onset of symptoms he had taken four tablets of scopolamine hydrobromide as a single dose $(1.2 \mathrm{mg})$ which belonged to a friend. He had not taken this preparation previously and denied taking any other medications. A diagnosis of anticholinergic toxicity secondary to scopolamine hydrobromide was made based on this information and his clinical picture. The patient was discharged later on the same day with slightly blurred vision. He was advised not to exceed the recommended dose of his medications and was also provided with a list of drugs with anticholinergic properties and advised to avoid these unless instructed otherwise by his doctor.

A review of the medical history revealed that the patient had presented 12 months earlier with similar, less severe symptoms consisting of slurred speech, difficulty in swallowing following ingestion of another anticholinergic agent, loperamide capsules for diarrhea. He had taken one capsule after each loose bowel action up to 12 capsules over 24 hours (recommended maximum is eight capsules over 24 hours).

\section{Discussions}

The symptoms observed in our patient are consistent with the anticholinergic syndrome, with peripheral and central manifestations, including myoclonic jerking, a symptom not often described in published case reports of scopolamine intoxication. Because of the information initially provided by the patient's family, symptoms were attributed to ingestion of an excessive dose of domperidone. However, a literature search did not retrieve any reports of an anticholinergic syndrome associated with this drug nor of interactions with scopolamine. ${ }^{24,25}$ This was confirmed by the manufacturer. In addition, the amount of domperidone ingested (40-60 mg) was not considered to be a significant overdose. ${ }^{24}$ It was subsequently established that the patient had ingested an unintentional overdose of scopolamine hydrobromide.

The recommended dose for adults is one to two tablets of $0.3 \mathrm{mg}$ as a single dose, repeated four to six hours later, if required, with a maximum dose of four tablets $(1.2 \mathrm{mg})$ over a 24-hour period. ${ }^{26}$ Our patient had taken $1.2 \mathrm{mg}$ as a single dose and symptoms appeared five hours later. This is consistent with an overdose of scopolamine, when manifestation of neurological symptoms is delayed. A similar, less severe reaction occurred on a previous occasion following ingestion of another anticholinergic agent, loperamide. Application of the Naranjo probability scale to our case report assigns the likelihood that the symptoms of anticholinergic toxicity were caused by scopolamine hydrobromide as "probable". ${ }^{27}$

The anticholinergic syndrome is well documented following therapeutic doses of transdermal scopolamine and following ocular instillation. This is compatible with the pharmacokinetics of the drug. Our case describes a central anticholinergic syndrome following $1.2 \mathrm{mg}$ of scopolamine hydrobromide, which is significantly lower than doses described in any published case report. Most of the published reports either do not specify the amounts involved or describe ingestion of scopolamine with other agents. When an amount is specified, doses of scopolamine hydrobromide 2.1 to $10 \mathrm{mg}$ produced symptoms of anticholinergic toxicity but this did not include seizure activity .,17,28

Our case suggests an increased susceptibility to anticholinegic effects of drugs. On two occasions the patient had exceeded the recommended dose by not adhering to the manufacturer's instructions. Most cases of anticholinergic intoxication can be treated by discontinuing the offending agent. ${ }^{16}$ However, for more serious cases it may be necessary to hospitalize the patient for close monitoring and observation. Benzodiazepines can be used to manage agitation and in our case, seizure activity. Supportive care is also necessary to cool the patient and maintain hydration. Patients who experience confusion and hallucinations should be monitored closely since they may be a danger both to themselves and others. ${ }^{16}$

A search of the database of the Australian Therapeutic Goods Administration's Adverse Drug Reaction Advisory Committee (ADRAC) from March 1986 to April 2009 revealed 14 reports of adverse reactions to one brand of scopolamine hydrobromide tablets, Kwells (Bayer Consumer Care, Pymble, NSW, Australia) and of these eight described symptoms of anticholinergic toxicity. During the same period there were 225 reports of anticholinergic syndrome associated with another nonprescription preparation containing scopolamine hydrobromide, Travacalm HO (Key Pharmaceuticals Pty. Ltd., Macquarie Park, NSW, Australia). Nearly all these reports, describing combinations of hallucinations, confusion, ataxia and blurred vision, were submitted to ADRAC in 2003. Travacalm was recalled and laboratory testing revealed that the scopolamine content of the tablets ranged from none to seven times the dose stated on the label. ${ }^{28}$ This highlights the importance of reporting adverse drug reactions to the relevant agencies. 


\section{Conclusion}

The unusual etiology makes this case a paradigmatic example of how a detailed medical history can help to achieve a correct diagnosis and in rationalizing any further investigations. It highlights the need to consider nonprescription products, ie, over-the-counter medications, herbal/nutritional supplements as causes of anticholinergic syndrome when a patient presents with symptoms suggestive of this diagnosis. ${ }^{13}$ This case illustrates that ingestion of scopolamine hydrobromide in doses which are marginally above the recommended range may produce symptoms of anticholinergic toxicity. In addition, some patients may be particularly susceptible to the anticholinergic effects of this drug and should be counseled accordingly. This case illustrates that the range of toxicity with respect to oral scopolamine is variable and unpredictable. Clinical judgment is more important than attempting to determine the amount ingested.

\section{Disclosures}

The authors report no conflicts of interest in this work.

\section{References}

1. Bruns JJ. Anticholinergic toxicity. eMedicine. Updated 2008 March 26; cited 2009 January 2. Available from: http://emedicine.medscape. com/article/812644-overview.

2. Hall RCW, Feinsilver DL, Holt RE. Anticholinergic psychosis: differential diagnosis and management. Psychosomatics. 1981; 22(7):581-587.

3. Hooper RG, Conner CS, Rumack BH. Acute poisoning from overthe-counter sleep preparations. JACEP. 1979;8:98-100.

4. Van Sassenbrocck D, Hemelsoet D, Vanwalleghem P, et al. Three cases of substitution errors leading to hyoscine hydrobromide overdose. Clin Toxicol (Phila). 2005;43:861-865.

5. Spinks AB, Wasiak J, Villaneuva EV, Bernath V. Scopolamine (hyoscine) for preventing and treating motion sickness. Cochrane Database Syst Rev. 2007;3:CD002851.

6. Renner UD, Oertel R, Kirch W. Pharmacokinetics and pharmacodynamics in clinical use of scopolamine. Ther Drug Monit. 2005;27(5): 655-665.

7. Clissold SP, Heel RC. Transdermal hyoscine (Scopolamine). A preliminary review of its pharmacodynamic properties and therapeutic efficacy. Drugs. 1985;29:189-207.

8. Lauwers LF, Daelemans R, Baute L, Verbraeken H. Scopolamine intoxications. Intens Care Med. 1983;9:283-285.

9. Scopolamine. Drug Facts and Comparisons: Pocket Version [online]. 2008. Saint Louis: Wolters Kluwer Health. Cited 2008 October 20. Available from Wolters Kluwer Health, Inc.
10. AHFS drug information. 2005. In: McEvoy GK, editor. Scopolamine. Bethesda, MD: American Society of Health-System Pharmacists; 2005. pp. 1254-1257.

11. Thomson Healthcare. Anticholinergic poisoning. In: Poisindex System. Cited 2009 July 17. Available from: http://www.thomsonhc.com.

12. Roig C, Rodriquez T, Solans T. Sindrome anticholinergico central secundario a colirio mydriatic. Neurologia. 1990;5(1):33-34.

13. Smith EA, Meloan CE, Pickell JA, Oehme FW. Scopolamine poisoning from homemade 'Moon Flower' wine. J Anal Toxicol. 1991;15:215-219.

14. Goldfrank L, Flomenbaum N, Lewin N, Weisman R, Howland MA Kaul B. Anticholinergic poisoning. J Toxicol Clin Toxicol. 1982;19(1): $17-25$.

15. Biggs JT, Spiker DG, Petit JM, Ziegler VE. Tricyclic antidepressant overdose. JAMA. 1977;238(2):135-138.

16. DeFrates LJ, Hoehns JD, Sakombut EL, Glascock DG, Tew AR. Antimuscarinic intoxication resulting from the ingestion of Moonflower seeds. Ann Pharmacother. 2005;39:173-176.

17. Ayub N, Donaldson D, Bedford D, et al. Lessons to be learned: a case study approach. J Roy Soc Health. 1997;117:242-244.

18. McEwen J, Thompson BR, Purcell PM, Kelly LF, Krauss AS. Widespread hyoscine hydrobromide toxicity due t contract manufacturer malpractice: the Travacalm episode. Drug Safety. 2007;30(5):375-378.

19. Samuels SI, Washington E. Coma and abnormal neurologic signs following premedication. Anesth Analg. 1980;59:79-80.

20. Elias M, Abouleish E. Scopolamine patch can be confusing to the patient and anesthesiologist: a case report. Anesthesiology. 1997;86(3): $743-744$.

21. Chan YC, Tse ML, Lau FL. Two cases of anticholinergic poisoning from transdermal scopolamine patch. Hong Kong Journal of Emergency Medicine. 2006;13(4):221-224.

22. Repéssé X, Geeraerts T, Pottecher J, Vigué B, Benhamou D, Duranteau J. [Coma with bilateral mydriasis after use of transdermal scopolamine in ICU.] Ann Fr Anesth Reanim. 2007;26:1070-1072.

23. Kranke P, Morin AM, Roewer N, Wulf H, Eberhart LH. The efficacy and safety of transdermal scopolamine for the prevention of postoperative nausea and vomiting: a quantitative systematic review. Anesth Analg 2002;95:133-143

24. Reddymasu S, Soykan I, McCallum W. Domperidone: review of pharmacology and clinical applications in gastroenterology. Am J Gastroenterol. 2007;102:2036-2045.

25. Robinson P. Dosage and drug interactions of domperidone. Am J Gastroenterol. 2008;103:1049.

26. Product information. Kwells (hyoscine hydrobromide). MIMS on-line. NSW: A division of CMPMedia Australia Pty Limited. Cited 2009 July 1. Available from: http://mims.hcn.net.au.

27. Naranjo CA, Busto U, Sellers EM, et al. A method for estimating the probability of adverse drug reactions. Clin Pharmacol Ther. 1981;30:239-245.

28. Adverse Drug Reactions Advisory Committee (ADRAC). Travacalm-your reports make a difference! Aust Adv Drug React Bull. 2003;22 (4):15-16. Available from: http://www.tga.gov.au/adr/aadrb/aadr0308.htm.
Therapeutics and Clinical Risk Management

\section{Publish your work in this journal}

Therapeutics and Clinical Risk Management is an international, peerreviewed journal of clinical therapeutics and risk management, focusing on concise rapid reporting of clinical studies in all therapeutic areas, outcomes, safety, and programs for the effective, safe, and sustained use of medicines. This journal is indexed on PubMed Central, CAS,

\section{Dovepress}

EMBase, Scopus and the Elsevier Bibliographic databases. The manuscript management system is completely online and includes a very quick and fair peer-review system, which is all easy to use. Visit http://www.dovepress.com/testimonials.php to read real quotes from published authors. 